Peer Effects in Team Sports: Empirical Evidence from NCAA Relay Teams

Craig A. Depken, II

Department of Economics

Belk College of Business

UNC-Charlotte

Charlotte, NC 28223

cdepken@uncc.edu

Lisa E. Haglund

Department of Economics

University of Texas - Arlington

Arlington, TX 76019

haglund@uta.edu 


\title{
Peer Effects in Team Sports: Empirical Evidence from NCAA Relay Teams
}

\begin{abstract}
This paper investigates whether disparity in team member quality impacts team production using NCAA $4 \times 400 \mathrm{~m}$ relay teams. The net peer effects are estimated to have both an absolute and relative negative effect on the team performance. Because NCAA relay teams are comprised of unpaid amateurs, we utilize a direct measure of team-member quality rather than indirect measures such as wages. The evidence suggests that a greater disparity in team member quality reduces team performance, that is, it increases a relay team's running time. This suggests that net negative peer effects exist and support the "team cohesiveness hypothesis" for NCAA relay teams.
\end{abstract}

JEL Classifications: J31, L20

Keywords: teamwork, shirking, track and field, sports 


\section{INTRODUCTION}

In a sport such as track and field, athletes are often primarily judged and therefore concerned with their own performance. However, in many cases, a high quality track and field athlete competes in numerous different events during a meet, some as an individual and others as a member of a team. Those instances in which an athlete is asked to compete on a team pose a potential moral hazard problem because increased effort during a team event might put them at a disadvantage in an individual competition.

This paper investigates whether positive or negative peer effects exist on $4 \times 400 \mathrm{~m}$ relay teams in National Collegiate Athletic Association (NCAA) Division I track and field. To assess whether relay teams experience peer effects, we estimate various empirical models that relate a team's absolute and relative performance to the average quality of its members, the standard deviation of its members' quality, the type of season, the type of race, the number of different runners on the team from the previous race, and the year of the race.

The results suggest that as the average team member quality ranking increases, team time decreases, i.e., absolute team performance improves. However, as the standard deviation of the team members' rankings increases, team time increases, i.e., absolute team performance decreases. We also find evidence that average quality improves a team's relative performance but disparity of quality reduces a team's relative performance. Furthermore, changing runners from race to race significantly reduces team performance.

\section{LITERATURE REVIEW}

The difference between a team and individual production function is that a team's production function is more than just the "summing up" of the individual team members' production 
functions. Instead, teams produce a combined output, where "there is a source of gain from cooperative activity involving working as a team, wherein individual cooperating inputs do not yield identifiable, separate products which can be summed to measure the total output" (Alchian and Demsetz 1972, 779). Although in many cases the output of a team will be greater than it would from the individuals working on their own, a team also has to deal with internal issues that the individual does not. These issues can affect the performance of workers dramatically, and can have positive or negative effects on the output of the team. Positive peer effects include knowledge transfers, increased esprit de corps, and improved marginal products. Negative peer effects, which exist if the output of worker $i$ systematically decreases the output of worker $j$ and vice versa, include problems such as jealousy, free riding, and shirking (Falk and Ichino, 2006).

Much of the existing literature in this area focuses on moral hazard and how uncooperative behavior amongst workers yields inefficient levels of output (Holmström, 1982). It is often assumed that by separating ownership and labor, the moral hazard problem can be resolved by more easily confirming what each team member contributes to total output.

To accomplish this, the ability to monitor workers is paramount. As suggested by Grossman and Hart (1983), the incentive to shirk will increase as monitoring can becomes more costly or infeasible. An alternative is to have employees monitor each other, which Barron and Gjerde (1997) coin a "peer pressure environment;" a combination of employee-provided standards, monitoring, and sanctions accepted and understood by workers before they each determine their individual levels of effort helps to mitigate the moral hazard problem. However, since a worker does not earn a higher payment when discovering the lazy behavior of another worker, she will only exert monitoring effort to the point where the "marginal gain of detection activity" equals "the marginal cost of detection" (Alchian and Demsetz, 1972). This, in turn, 
implies less productive effort and greater shirking than when monitoring is costless. Moreover, even if a team member knows another team member is not doing as much as he could, it might not be in her best interest to tell the manager about this behavior even though it decreases team performance. If the person shirking is better than an alternative (non-shirking) team member, then it might be better to keep the shirking member on the team.

Team externalities exist when an individual's performance cannot be completely and accurately measured. Team externalities cause all workers to share credit or blame equally, which augments the incentive to shirk (Drago and Turnbull, 1988). A lower effort by one individual might decrease overall team output, the blame for which is shared by all team members. This, in turn, motivates other team members to decrease their level of effort.

Problems can also occur if a conflict of interest exists, i.e., the objectives of individual workers are not the same as the objectives of the team (Groves 1973). A relay teams can be compared to a conglomerate, considering each team member a separate unit and the coach as the central administration. In this model, the team members are linked only through the coach, and might not agree with all the decisions made for them by the coach. For example, their opinion about maximum performance or racing decisions might not be the same as that of the coach. Therefore, it might be in the team members' interest to lie or give the coach imperfect information, thereby making it easier to shirk. However, this is likely less of a problem at schools with great team spirit or a strong history in a certain event, such as the $4 \times 400 \mathrm{~m}$ relay, where team members have a common goal, and the athletes who go there do so because they want to be part of that particular team.

Along with the problem of incentives is the concern of how the workers should be compensated. Lazear and Rosen (1981) suggest that when "inexpensive and reliable monitors of 
effort are available, the best compensation scheme is a periodic wage based on input." On the other hand, when monitoring becomes a problem, workers should be paid based on rank order, that is on their relative position in the organization. This second alternative is usually how track athletes within NCAA are compensated, that is, based on their relative rank or performance within the team as a whole. Those student athletes with a full scholarship should generally those who score the most points during events and can qualify for the regional and national championships.

Another topic discussed in the context of negative peer effects and moral hazard is the allocation of workers. Sanderson and Siegfried (2003) suggest that when spillovers are significant, workers should be sorted and grouped according to ability: high-quality workers should be teamed with other high-quality workers. The only problem in this situation is how to sort these common groups so that output is maximized.

The confidence in other team members is based on how much trust there is between the members. Trust can help a team by increasing the information available to the principal and the other team members (Jones and George, 1998). This can give rise to better cooperation and improved performance. Teams with strong team spirit have a strong advantage in these circumstances as "shared values result in strong desire to cooperate, even at personal expense" (Jones and George, 1998). Sports teams try to encourage a strong sense of team spirit and loyalty so that team members want to be part of the team and no one wants to shirk. Indeed, this focus on team spirit can cause managers to "over invest" in training athletes and cause "reverse shirking” (Alchian and Demsetz, 1972).

Even though athletes under NCAA Division I are considered amateur athletes and do not receive monetary wages for their performance, in many ways NCAA sports teams are similar to 
professional sports teams. As pointed out by Carmichael, Thomas and Ward (2000), "[i]n many sports, the isolation and identification of individual contributions is problematic, if not impossible, due to the continuously interactive nature of a match or game." This can make it difficult to estimate whether positive or negative net peer effects exist in a team environment.

Since peer effects can be hard to measure directly, an alternative approach is necessary. Depken (2000), and several authors following his example, have investigated the whether the quality of professional sports teams responds to the level and disparity of player salaries. The team-cohesiveness hypothesis (Levine, 1991) posits that wage disparity will reduce team productivity by inciting jealousy and less cooperation amongst team members. On the other hand, the danger potential hypothesis (Ramaswamy and Rowthorne, 1991) is essentially an efficiency wage argument and suggests that those workers whose shirking can cause the greatest damage to team output should be paid the most, i.e., wage disparity should be correlated with increased team productivity.

In professional baseball, Depken found that a higher disparity in wages on led to a reduction in team performance. Other authors have confirmed this result in baseball but have shown that the danger potential hypothesis might prevail in other sports.

The main difference between the current study and those in professional sports is the lack of formal wages in the NCAA; athletes are instead given an in-kind payment. Therefore, rather than look at the impact of the remuneration pattern on team output, we focus directly on the inputs to team productivity. That is, we test if greater disparity in worker quality leads to a reduction in team performance due to negative peer effects. 


\section{NCAA RELAY TEAM PERFORMANCE AND PEER EFFECTS}

The performance of a relay team, measured in time, can be considered a function of the actual performance of the four runners on the team, where each runner's performance $A_{i}$ is a function of runner's quality, $Q_{i}$, and the quality of the other team members, $Q_{\sim i}$. That is, the team production function can be defined as Time $=f\left(A_{1}(Q), A_{2}(Q), A_{3}(Q), A_{4}(Q)\right)+\varepsilon$, where $\mathrm{A}_{\mathrm{i}}$ is the actual output of team member $i$ and $Q=\left[Q_{1}, Q_{2}, Q_{3}, Q_{4}\right]$ is a vector of each team member's expected quality, and $\varepsilon$ is a random error term. The partial effect of $Q_{j}$ on $A_{i}$ reflects the peer effects of runner $j$ on runner $i$. The net influence of the combination of peer effects on runner $i$ 's actual production can be positive or negative. A net positive peer effect will induce the team member to run faster, whereas negative peer effects would induce the runner to run slower. In this study, I will only be able to estimate a reduced form of the net impact of peer effects on a team level. That is, I cannot identify how any particular runner influences the other runners on the team.

A coach can try to improve the performance of a team by changing the combination of the team members, and replacing one runner with a runner of higher quality. In this case, the coach is hoping to get a reduction in the team's time by changing the $\mathrm{j}^{\text {th }}$ runner, that is, $\frac{\partial A_{j}}{\partial Q_{j}}>0$. However, this will only be the case if, in fact, the total output of the new team member is positive, $\frac{\partial T}{\partial Q_{i}}=\sum_{i=1}^{4} \frac{\partial f}{\partial A_{i}} * \frac{\partial A_{i}}{\partial Q_{j}}$, where $\frac{\partial A_{i}}{\partial Q_{j}}$ reflects positive or negative peer effects of team member $j$ on team member $i$. The actual impact of changing a runner can be positive or negative depending on the peer effects caused by the change in quality of the $j^{\text {th }}$ team member.

If an increase in quality improves the aggregate performance of the team members, this would mean that the team members responded positively to the new combination of runners, and 
the time of the relay would decrease. Here, the gains from improved quality would be greater than any negative effects experienced by any of the other runners. On the other hand, if the actual performance of the team decreases after the change of team members, despite any increase in quality, then there are negative peer effects that reduce team output.

\section{EMPIRICAL SPECIFICATIONS AND DATA}

To test for positive or negative peer effects we control for both the average and the standard deviation of team member quality. If the standard deviation is found to have an insignificant relationship with team output, this would suggest that there are no net peer effects caused by disparity of team member quality. If the standard deviation is significant and positive, this would suggest the existence of net negative peer effects; the greater the disparity of talent on a relay team the worse the team performs, ceteris paribus. The team production function estimated model specified as:

TIME $=\beta_{0}+\beta_{1}$ AVERANK $+\beta_{2}$ AVERANK $^{2}+\beta_{3}$ SDRANK $+\beta_{4}$ SDRANK $^{2}+\beta_{5}$ OUTDOORS $+\beta_{6}$ FINALS $+\beta_{7}$ PRELIMS $+\beta_{8}$ NUMDIFF $+\gamma \cdot$ YEAR $+\varepsilon$,

where the dependent variable, TIME, is the number of seconds a relay team runs the $4 \times 400 \mathrm{~m}$, the $\beta$ 's are parameters to be estimated and $\varepsilon$ is a zero-mean error term.

The explanatory variables include the average ranking of a particular team's members, $A V E R A N K$, and its quadratic; the standard deviation of the team member's ranking, SDRANK, and its quadratic; the number of different runners on the team compared to the previous race, NUMDIFF; and control variables for whether the race was held outdoors rather than indoors, OUTDOORS, and whether the race was an NCAA championship finals or NCAA championship preliminary, FINALS and PRELIMS, respectively. 
The variable $A V E R A N K$ is expected to have an inverse relationship with time, that is, a one unit increase in the average ranking of the team members will result in a faster time. The parameter SDRANK, on the other hand, could be either positive or negative since the range of the ranking on the team can result from any combination of runners. The team could include three average runners and one all-star, or it could be three all-star and one average runner. However, when comparing two teams with the same average ranking, the sign of the parameter on SDRANK provides evidence as to whether the average team suffers from negative peer effects, ceteris paribus.

The parameter NUMDIFF is expected to have a positive relationship with the dependent variable. The more runners that have been part of a particular team over the year, the slower the time will be as the team members will have less confidence and trust in each other. The variables controlling for race conditions the type of race of a particular observation are expected to have an inverse relationship with time compared to their respective reference categories

To test for possible negative peer effects, three different approaches are taken. First, the basic specification given in equation (1) is estimated using robust ordinary least squares. To determine whether a team is under-performing or over-performing given its inputs, we create a measure of predicted team quality and compare that to the team's actual quality; the difference is used to test whether peer effects reduce team effectiveness in a relative rather than an absolute sense. Finally, we estimate a model wherein the dependent variable takes a value of one if the team is found to be under-performing. This last model allows us to test whether certain variables influence the probability that a team will under-perform.

The data describe 305 teams running twenty-four different $4 \times 400 \mathrm{~m}$ relay races at NCAA Division I regional and NCAA championship track and field meets from 2002 through 2006. To 
make sure that all team members would be individually ranked, we only included results from the NCAA Regional meets and NCAA Championship meets, which all have qualifying standards. For the regional meet and the indoor championship, only finals take place, whereas in the outdoor championship, teams run both prelims and finals.

Each team member's national ranking, as generated by Trackshark.com, is converted to the point system used by the International Association of Athletics Federation (IAAF), where each runner's season-best time is worth a certain amount of points. All times on the ranking lists were converted to a non-banked $200 \mathrm{~m}$ track at sea-level even if the runner raced on a banked or over-long track or if they were at high altitude. The points for all four team members are used to determine the mean and standard deviation of quality for each team.

Only teams on which all players were individually ranked are included in the sample. By only including teams with all players ranked, 928 observations were deleted, that is, 232 teams, leaving me with 292 observations ( 73 teams). However, of those 73 teams, three of them did not have an official time from the race. That is, they were either disqualified during the race, or did not start the race at all. Therefore, these observations were dropped from the sample. The final sample is comprised of 280 observations for 70 teams. ${ }^{1}$ Variable definitions and sources are provided in Table 1 and the sample descriptive statistics are reported in Table 2.

\section{EMPIRICAL RESULTS}

The empirical results for three different models are reported in Table 3 and Table 4 . The first model entails robust OLS on the empirical specification provided in equation (1) above. ${ }^{2}$ The

\footnotetext{
${ }^{1}$ This does introduce the possibility of sample selection bias. We hope to address this issue in the future.

${ }^{2}$ A White test statistic was 267.73 with a p-value of 0.000 .
} 
reduced form parameters are all statistically significant at the $1 \%$ level except for the standard deviation of team member quality, which is significant at the 5\% level.

The results from the regression output for the basic OLS model reflect the absolute effect of the disparity on team performance. As the average quality of the athletes on a team increases, the team's time drops, i.e., the relay team runs faster. However, the returns to average quality are diminishing, as reflected in the positive parameter estimate on $A V E R A N K S Q{ }^{3}$ A scatter plot of TIME against the average team quality $(A V E R A N K)$ in Figure 1 confirms the non-linear relationship between team performance and average team member quality.

The impact of quality disparity on team performance is negative. Having a greater disparity of quality amongst team members increases a team's time suggesting net negative peer effects from quality disparity. However, there is a non-linear relationship between disparity and team performance, as the scatter plot of TIME against SDRANK in Figure 2 confirms. There is a sufficient level of quality disparity at which point the performance of the team will actually improve, ceteris paribus. This suggests that a team with one or two very high quality runners can perform better than a the team comprised of four relatively similar runners.

To be a bit more specific about the results, the estimates indicate that a one unit increase in the average team member ranking reduces the time by 1.83 seconds, whereas an increase in the average ranking squared increases time by 0.001 seconds. Running a race outdoors reduces time by 3.54 seconds, ceteris paribus. Preliminary times are 2.24 seconds faster on average than regional races, ceteris paribus, and final races are 3.86 seconds faster on average than regional

\footnotetext{
${ }^{3}$ The hypothesis that the two variables, $A V E R A N K$ and $A V E R A N K S Q$, are jointly equal to zero is rejected with an Ftest statistic of 64.42 and a p-value of 0.0000 .
} 
races, ceteris paribus. Finally, each replaced team member team from race to race increases time by 0.83 seconds, ceteris paribus.

As a robustness check, Model (1) in Table 1 was re-estimated including an additional variable, ALLSTAR, which takes a value of one if the team has an all-star. This was done to check whether an all-star on the team changes the parameter of the standard deviation of the team members' ranking since an all-star definitely would increase the range of the runners' quality. The variable ALLSTAR takes a value of one if any team member's quality was one and a half standard deviations above the mean quality in the sample; thirty-two of the runners qualified as all-stars. However, the interactions of the variable with the average and standard deviation of quality proved insignificant. We conclude from this that having all-stars on relay teams provides no additional net peer effects, positive or negative. The constant variable is only an intercept term, and will therefore not bring too much information to the analysis. Yet, based on the assumption that all other variables are zero, the time for the relay would be about 1249.47 seconds, which would be a time over 20 minutes.

The standard deviation of the team members' ranking has a positive relationship with time; a one-unit increase in the standard deviation of team member rankings corresponded with an increase the time of 0.06 seconds, ceteris paribus. However, the negative effects of quality disparity are diminishing; a one-unit increase in the standard deviation squared decreases the time of the relay with 0.007 seconds, ceteris paribus.

There is some concern that the results in Model (1) suffer from an omitted variable bias, specifically unmeasured team-specific heterogeneity such as coaching, training, and team spirit. We re-estimated the model including team fixed effects; the results are reported in Model (2) in 
Table $3 .{ }^{4}$ Having controlled for team-fixed effects, the parameter estimates on SDRANK and SDRANKSQ have the same sign and remain significant as does the parameter estimate for NUMDIFF. These results show that the net negative peer effects on the relay teams remain even after controlling for issues such as coaching ability and program history. The estimated team fixed-effects are reported in Table 4. As can be seen, only ten out of the twenty fixed effects are statistically different from zero.

Having established that disparity of quality reduces team productivity in an absolute sense, it of interest whether disparity of quality reduces team productivity in a relative sense. To test this, we converted the time each team actually ran into a set of points, using the same conversion table as for the individual rankings, and subtracted the average ranking of the team. The resultant variable, $D P E R F$, measures the difference in actual performance from expected performance of a particular team. Using DPERF as the dependent variable allows us to test whether race and team characteristics correlate with teams over or under achieving.

Model (3) and Model (4) report robust OLS results using DPERF as the dependent variable, Model (4) includes team fixed effects. In this specification, all of the main variables are again significant at the $5 \%$ level, and 8 of the 20 teams have statistically significant fixed effects. The results suggest that a marginal change in average quality improves relative team performance, but that team member disparity reduces a team's relative performance. This means that a greater disparity in team member quality, the average team performs worse than its average quality rating would predict. This provides strong evidence for the existence of negative peer effects created by disparity of team member quality.

\footnotetext{
${ }^{4}$ The reference team in this model is Arizona State University.
} 
The final specification is to estimate a probit model in which the dependent variable, UNDERPERF, takes a value of one if the team under-performed and zero otherwise. The results from the probit model shows that the greater the average quality the lower the probability of a team underperforming (see column (5) of Table 3). However, in this case, the disparity of team member quality doesn't correspond with a statistically significant increase in the probability that a team will under-perform. However, if the variable NUMDIFF is removed, the standard deviation and its quadratic again become significant. This suggests that the negative peer effects generated by replacement players alone rather than any change in quality disparity that arises from replacement runners might dominate.

\section{CONCLUSIONS}

This paper shows that a disparity in team member quality reduces the performance of NCAA men's $4 x 400 \mathrm{~m}$ relay teams. We associate this reduction in team productivity to negative peer effects. Starting with a basic OLS model, we find that team relay time is positively related to average quality but negatively related to the standard deviation in quality. Further, teams that change runners from one race to the next suffer a reduction in team performance. The results are robust to including team fixed-effects and strongly suggest that there are net negative peer effects associated with team member quality disparity.

We also investigate whether average quality and the disparity of quality impact the relative performance of a team, that is, is a team's actual time faster or slower than would be predicted given their average quality. The results suggest that the net negative peer effects impact the relative performance of a team in addition to the absolute performance. 
Finally, we relate the various race and team characteristics to a dummy variable that takes a value of one if the team underperformed. This model shows that a marginal change in the average quality decreases the probability that the team under-performs, but the standard deviation of team member quality only increases the odds that a team underperforms if the number of different runners from one race to the next is dropped from the model.

These results suggest that greater disparity in team member quality increases NCAA relay team times, which suggests the existence of negative peer effects. These negative peer effects can arise because of free riding or shirking, but could also arise from other non-monetary reasons such as jealousy, mistrust, or a lack of familiarity. The results add to the literature investigating the impact of wage disparities on team performance and offers further support to the team cohesiveness hypothesis that has been shown to hold in professional baseball. 
Table 1: Variable Definitions

\begin{tabular}{|l|l|l|}
\hline Variable & Description & Source \\
\hline TIME & The final time of the 4x400m relay (seconds) & Trackshark.com \\
\hline AVERANK & The average quality of the team & Trackshark.com \& IAAF.org \\
\hline AVERANKSQ & The average quality squared & Authors' calculations \\
\hline SDRANK & The standard deviation of the team members' quality & Authors' calculations \\
\hline SDRANKSQ & The standard deviation squared & Authors' calculations \\
\hline OUTDOORS & The race is run outdoors & Trackshark.com \\
\hline INDOORS & The race is run indoors & Trackshark.com \\
\hline FINALS & The race is a final race & Trackshark.com \& NCAA.com \\
\hline PRELIMS & The race is a prelim race & Trackshark.com \& NCAA.com \\
\hline REGIONALS & The race is a regional race & Trackshark.com \& NCAA.com \\
\hline NUMDIFF & $\begin{array}{l}\text { The number of different runners on a particular team } \\
\text { from one race to the other }\end{array}$ & Authors' calculations \\
\hline DRANK & $\begin{array}{l}\text { The difference between the actual quality and the } \\
\text { expected quality of the team }\end{array}$ & $\begin{array}{l}\text { IAAF.org, and authors' } \\
\text { calculations }\end{array}$ \\
\hline UNDERPERF & $\begin{array}{l}\text { The difference between the actual and expected } \\
\text { quality of the team is negative }\end{array}$ & Authors' calculations \\
\hline ALLSTAR & $\begin{array}{l}\text { A runner's ranking is more than one and a half } \\
\text { standard deviation above the sample mean }\end{array}$ & Authors' calculations \\
\hline
\end{tabular}


Table 2: Descriptive Statistics

\begin{tabular}{|l|c|c|c|c|}
\hline Variable & Mean & Std. Dev & Min & Max \\
\hline TIME & 185.115 & 3.654 & 179.59 & 202.43 \\
\hline AVERANK & 1109.581 & 30.206 & 1051.75 & 1174.375 \\
\hline AVERANKSQ & 1232079 & 67342.12 & 1106178 & 1379157 \\
\hline SDRANK & 35.653 & 15.498 & 11.247 & 74.293 \\
\hline SDRANKSQ & 1510.535 & 1224.271 & 126.5 & 5519.5 \\
\hline OUTDOORS & 0.957 & 0.202 & 0 & 1 \\
\hline INDOORS & 0.042 & 0.202 & 0 & 1 \\
\hline FINALS & 0.342 & 0.475 & 0 & 1 \\
\hline PRELIMS & 0.3 & 0.459 & 0 & 1 \\
\hline REGIONALS & 0.357 & 0.480 & 0 & 1 \\
\hline NUMDIFF & 0.685 & 0.995 & 0 & 4 \\
\hline DRANK & -1.25 & 46.200 & -231.375 & 59.187 \\
\hline UNDERPERF & 0.471 & 0.500 & 0 & 1 \\
\hline ALLSTAR & 0.103 & 0.305 & 0 & 1 \\
\hline
\end{tabular}


Table 3: Estimation Results

\begin{tabular}{|c|c|c|c|c|c|c|}
\hline & $(1)$ & $(2)$ & (3) & (4) & $(5)$ & $(6)$ \\
\hline Variable & $\begin{array}{c}\text { Robust OLS } \\
\text { (TIME) }\end{array}$ & $\begin{array}{c}\text { Fixed } \\
\text { Effects } \\
\text { (TIME) }\end{array}$ & $\begin{array}{c}\text { Robust OLS } \\
\text { (DRANK) }\end{array}$ & $\begin{array}{l}\text { Fixed Effects } \\
\text { (DRANK) }\end{array}$ & $\begin{array}{c}\text { Probit } \\
\left(_{(U N D E R P E R F)}{ }^{a}\right.\end{array}$ & $\begin{array}{c}\text { Marginal } \\
\text { Effect } \\
\mathrm{d}(\mathrm{P}=1) / \mathrm{dX}\end{array}$ \\
\hline \multirow[t]{2}{*}{ AVERANK } & -1.834 & -3.512 & 26.553 & 51.631 & -1.043 & -0.416 \\
\hline & $(4.72)^{* *}$ & $(7.68)^{* *}$ & $(4.55)^{* *}$ & $(7.30)^{* *}$ & $(3.90)^{* *}$ & \\
\hline \multirow[t]{2}{*}{ AVERANKSQ } & 0.001 & 0.002 & -0.012 & -0.023 & 0.000 & 0.000 \\
\hline & $(4.55)^{* *}$ & $(7.55)^{* *}$ & $(4.55)^{* *}$ & $(7.32)^{* *}$ & $(3.95)^{* *}$ & \\
\hline \multirow[t]{2}{*}{ SDRANK } & 0.061 & 0.196 & -0.888 & -2.846 & 0.009 & 0.004 \\
\hline & $(2.21)^{*}$ & $(4.89)^{* *}$ & $(2.17)^{* *}$ & $(3.63)^{* *}$ & $(0.46)$ & \\
\hline \multirow[t]{2}{*}{ SDRANKSQ } & -0.001 & -0.002 & 0.011 & 0.026 & -0.000 & 0.000 \\
\hline & $(2.32)^{*}$ & $(3.27)^{* *}$ & $(2.33)^{* *}$ & $(3.20)^{* *}$ & $(1.77)$ & \\
\hline \multirow[t]{2}{*}{ OUTDOORS } & -3.544 & -2.831 & -46.920 & -58.610 & & \\
\hline & $(4.99)^{* *}$ & $(3.59)^{* *}$ & $(4.39)^{* *}$ & $(4.90)^{* *}$ & & \\
\hline \multirow[t]{2}{*}{ FINALS } & -3.861 & -2.940 & 59.201 & 45.594 & -2.407 & $-0.723^{b}$ \\
\hline & $(9.91)^{* *}$ & $(8.70)^{* *}$ & $(10.12)^{* *}$ & $(10.44)^{* *}$ & $(6.57)^{* *}$ & \\
\hline \multirow[t]{2}{*}{ PRELIMS } & -2.241 & -1.945 & 33.743 & 29.478 & -1.184 & $-0.435^{b}$ \\
\hline & $(6.56)^{* *}$ & $(6.93)^{* *}$ & $(6.64)^{* *}$ & $(7.38)^{* *}$ & $(5.24)^{* *}$ & \\
\hline \multirow[t]{2}{*}{ NUMDIFF } & 0.831 & 0.761 & -12.345 & -11.270 & 0.455 & 0.181 \\
\hline & $(4.77)^{* *}$ & $(5.45)^{* *}$ & $(4.81)^{* *}$ & $(6.18)^{* *}$ & $(5.07)^{* *}$ & \\
\hline \multirow[t]{2}{*}{ YEAR 2003} & -3.064 & -3.964 & 45.903 & 58.525 & -6.942 & $-0.694^{b}$ \\
\hline & $(5.33)^{* *}$ & $(3.63)^{* *}$ & $(5.36)^{*}$ & $(3.48)^{* *}$ & $(14.50)$ & \\
\hline \multirow[t]{2}{*}{ YEAR 2004} & -4.023 & -5.807 & 61.281 & 87.081 & -7.014 & $-0.985^{b}$ \\
\hline & $(8.27)^{* *}$ & $(5.42)^{* *}$ & $(8.37)^{* *}$ & $(5.70)^{* *}$ & $(17.36)$ & \\
\hline \multirow[t]{2}{*}{ YEAR 2005} & -4.516 & -6.254 & 68.666 & 93.864 & -7.160 & $-0.997^{b}$ \\
\hline & $(8.52)^{* *}$ & $(6.01)^{* *}$ & $(8.82)^{* *}$ & $(5.51)^{* *}$ & $(18.57)$ & \\
\hline \multirow[t]{2}{*}{ YEAR 2006} & -4.111 & -4.854 & 62.416 & 72.537 & -7.712 & $-0.945^{b}$ \\
\hline & $(8.29)^{* *}$ & $(4.47)^{* *}$ & $(8.55)^{* *}$ & $(4.66)^{* *}$ & $(18.38)$ & \\
\hline \multirow[t]{2}{*}{ CONSTANT } & $1,249.478$ & $2,182.171$ & $-14,788.200$ & $-28,724.673$ & 581.119 & \\
\hline & $(5.79)^{* *}$ & $(8.55)^{* *}$ & $(4.57)^{* *}$ & $(7.28)^{* *}$ & $(3.90)$ & \\
\hline Observations & 280 & 280 & 280 & 280 & 268 & 268 \\
\hline R-squared & 0.59 & 0.81 & 0.44 & 0.74 & & \\
\hline F-test/ X -test & & 34.57 & 17.47 & 22.75 & 150.88 & \\
\hline
\end{tabular}


Table 4: Team Fixed Effects

\begin{tabular}{|c|c|c|}
\hline & $\begin{array}{c}(2) \\
\text { Team Fixed Effects }\end{array}$ & $\begin{array}{c}(4) \\
\text { Team Fixed Effects }\end{array}$ \\
\hline \multirow[t]{2}{*}{ Baylor } & -0.960 & 14.427 \\
\hline & $(1.16)$ & $(1.01)$ \\
\hline \multirow[t]{2}{*}{ Brigham Young } & 1.982 & -30.113 \\
\hline & $(2.63)^{* *}$ & $(2.22)^{* *}$ \\
\hline \multirow[t]{2}{*}{ Clemson } & -1.666 & 23.673 \\
\hline & $(1.29)$ & $(1.60)$ \\
\hline \multirow[t]{2}{*}{ Florida } & 1.105 & -16.686 \\
\hline & $(1.99)^{*}$ & $(1.38)$ \\
\hline \multirow[t]{2}{*}{ Georgetown } & -0.937 & 13.940 \\
\hline & $(0.78)$ & $(1.06)$ \\
\hline \multirow[t]{2}{*}{ Hampton } & 3.118 & -46.618 \\
\hline & $(3.19)^{* *}$ & $(2.61)^{* *}$ \\
\hline \multirow[t]{2}{*}{ Illinois } & 6.814 & -98.641 \\
\hline & $(8.42)^{* *}$ & $(3.62)^{* *}$ \\
\hline \multirow[t]{2}{*}{ Kentucky } & 1.584 & -22.812 \\
\hline & $(1.42)$ & $(1.53)$ \\
\hline \multirow[t]{2}{*}{ LSU } & -1.273 & 19.994 \\
\hline & $(2.11)^{*}$ & $(1.92)$ \\
\hline \multirow[t]{2}{*}{ Minnesota } & -0.142 & 2.475 \\
\hline & $(0.20)$ & $(0.19)$ \\
\hline \multirow[t]{2}{*}{ Mississippi State } & -0.302 & 4.731 \\
\hline & $(0.40)$ & $(0.35)$ \\
\hline \multirow[t]{2}{*}{ Nebraska } & 3.121 & -44.431 \\
\hline & $(2.29)^{*}$ & $(2.70)^{*}$ \\
\hline \multirow[t]{2}{*}{ Oregon } & -0.862 & 13.782 \\
\hline & $(1.17)$ & $(0.96)$ \\
\hline \multirow[t]{2}{*}{ Sam Houston State } & -6.215 & 92.994 \\
\hline & $(4.44)^{* *}$ & $(6.12)^{* *}$ \\
\hline \multirow[t]{2}{*}{ South Carolina } & -1.060 & 15.537 \\
\hline & $(1.55)$ & $(1.21)$ \\
\hline \multirow[t]{2}{*}{ TCU } & 0.851 & -12.370 \\
\hline & $(1.04)$ & $(0.86)$ \\
\hline \multirow[t]{2}{*}{ Texas Tech } & 1.963 & -28.498 \\
\hline & $(2.96)^{* *}$ & $(1.89)^{* *}$ \\
\hline \multirow[t]{2}{*}{ UCLA } & 3.122 & -48.301 \\
\hline & $(4.30)^{* *}$ & $(3.59)^{* *}$ \\
\hline \multirow[t]{2}{*}{ USC } & -2.111 & 31.525 \\
\hline & $(2.48)^{*}$ & $(2.57)^{*}$ \\
\hline
\end{tabular}


Figure 1: Scatter plot of time and the team members' average ranking

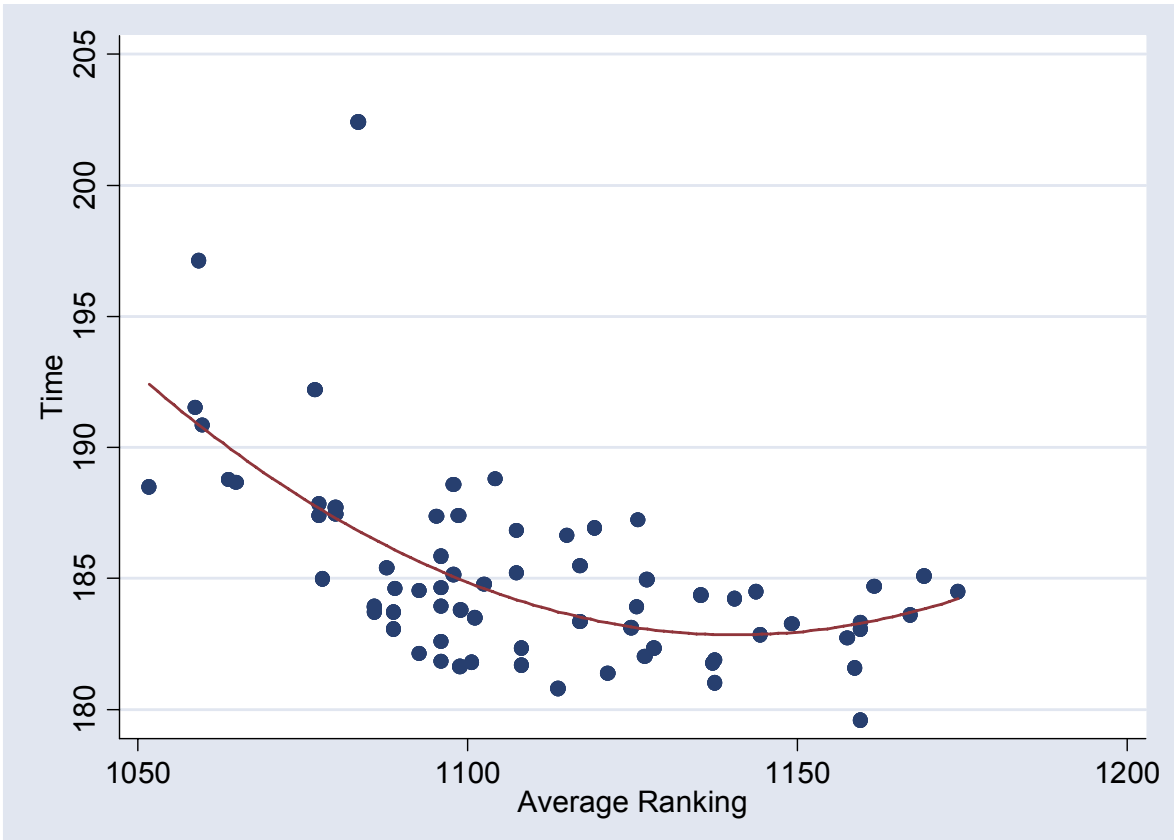

Figure 2: Scatter plot of time and the team members' average ranking

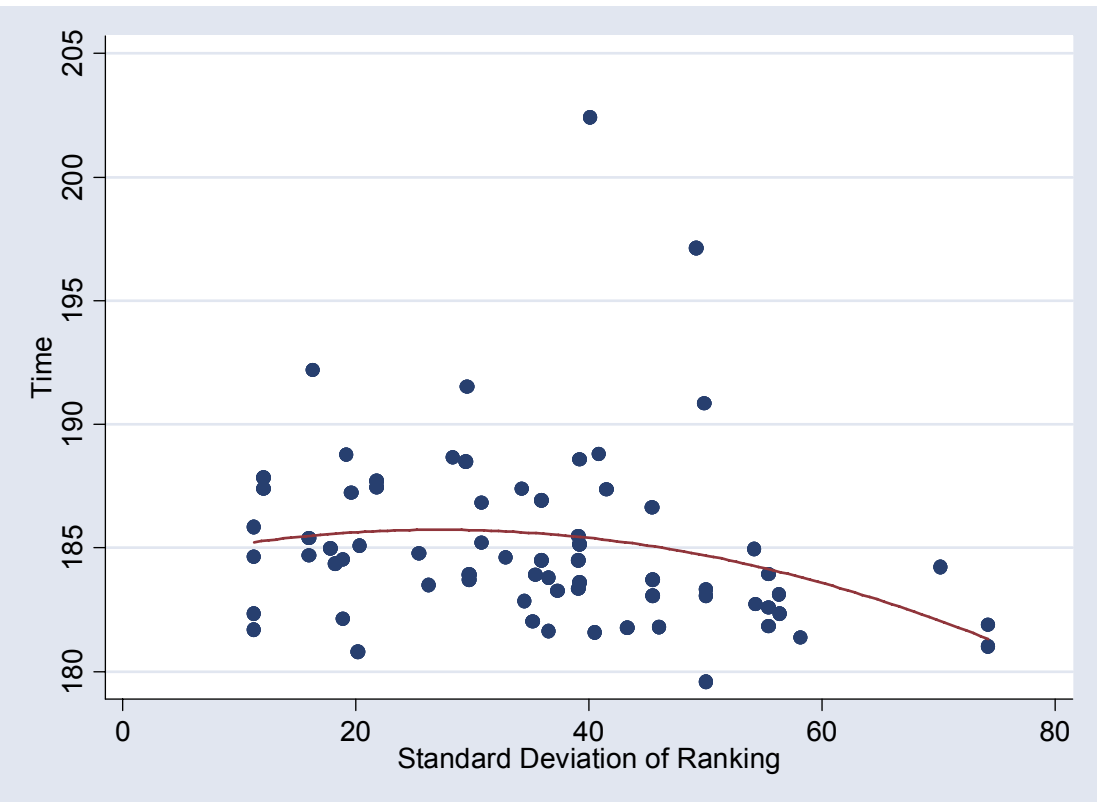




\section{REFERENCES}

Alchian, Armen A., and Harold Demsetz. "Production, Information Costs, and Economic Organization". The American Economic Review. 62.5 (1972): 777-795.

Barron, John M. and Kathy Paulson Gjerde. "Peer Pressure in an Agency Relationship". Journal of Labor Economics. 15.2 (1997): 234-254.

Carmichael, Fiona, Dennis Thomas, and Robert Ward. "Team Performance: The Case of English Premiership Football”. Managerial and Decision Economics. 21.1 (2000): 31-45.

Depken, Craig A. "Wage Disparity and Team Productivity" Evidence from Major League Baseball”. Economic Letters. 67.1 (2000): 87-92.

Drago, Robert, and Geoffrey K. Turnbull. "The Incentive Effects of Tournaments with Positive Externalities among Workers". Southern Economic Journal. 55.1 (1988): 100-106.

Falk, Armin, and Andrea Ichino. "Clean Evidence on Peer Effects". Journal of Labor Economics. 24.1 (2006): 39-57.

Grossman, Sanford J., and Oliver D. Hart. "An Analysis of the Principal-Agent Problem". Econometrica. 51.1 (1983): 7-45.

Groves, Theodore. "Incentives in Teams". Econometrica. 41.4 (1973): 617-631.

Holmström, Bengt. "Moral Hazard and Observability". The Bell Journal of Economics. 10.1 (1979): 74-91.

---, "Moral Hazard in Teams". The Bell Journal of Economics. 13.2 (1982): 324-340.

IAAF International Association of Athletics Federations. 1996. International Association of Athletics Federations. Jan $102007<$ http://www.iaaf.org>.

Jones, Gareth R., and Jennifer M. George. "The Experience and Evolution of Trust: Implications for Cooperation and Teamwork". The Academy of Management Review. 23.3 (1998): 531546.

Lazear, Edward P., and Sherwin Rosen. "Rank-Order Tournaments as Optimum Labor Contracts". The Journal of Political Economy. 89.5 (1981): 841-864. 
National Collegiate Athletic Association (2006), www.ncaa.org, last accessed Dec. 20, 2006

National Collegiate Athletic Association (2003), NCAAsports.com, last accessed Dec 202006 $<$ http://www.ncaasports.com>.

Ramaswamy, R. and Rowthorne, R.E. "Efficiency Wages and Wage Dispersion”. Economica, 58 (1991), 501-514.

Sanderson, Allen R., and John J. Siegfried. "Thinking about Competitive Balance". Journal of Sports Economics. 4.4 (2003): 255-279.

Trackshark.com: College Track \& Field. 2002. Ed. Tom Borish. Dec 232006

$<\mathrm{http}: / /$ www.trackshark.com>. 